\title{
eReuse poster: the circular economy of digital devices
}

\author{
LEANDRO NAVARRO, Universitat Politècnica de Catalunya, Spain \\ MIREIA ROURA, Universitat Politècnica de Catalunya, Spain \\ DAVID FRANQUESA, Universitat Politècnica de Catalunya, Spain \\ ROC MESEGUER, Universitat Politècnica de Catalunya, Spain
}

\begin{abstract}
eReuse is an initiative and action-research project that since 2015 has iterated over research and activism to understand, develop, apply to communities, evaluate and scale-up the circular economy of digital devices. The work, in partnership with diverse organisations, has contributed to the transition towards a circular economy of digital devices that contributes effectively to sustainable development.
\end{abstract}

CCS Concepts: $\bullet$ Human-centered computing $\rightarrow$ Social content sharing; $\bullet$ Networks $\rightarrow$ Location based services; $\bullet$ Hardware $\rightarrow$ Impact on the environment; • Social and professional topics $\rightarrow$ Governmental regulations.

Additional Key Words and Phrases: Circular economy, digital devices, sustainability, platform cooperativism, environmental impact, social impact, climate change, software tools, dataset, public policy, distributed ledger technology.

\section{ACM Reference Format:}

Leandro Navarro, Mireia Roura, David Franquesa, and Roc Meseguer. 2021. eReuse poster: the circular economy of digital devices. In ACM SIGCAS Conference on Computing and Sustainable Societies (COMPASS) (COMPASS '21), fune 28-fuly 2, 2021, Virtual Event, Australia. ACM, New York, NY, USA, 5 pages. https://doi.org/10.1145/3460112.3471973

\section{SUSTAINABLE DEVELOPMENT WITH A CIRCULAR ECONOMY OF DIGITAL DEVICES}

Sustainable development is about meeting "the needs of the present without compromising the ability of future generations to meet their own needs" (the Brundtland Commission Report, 1987 [15]). Sustainable development can be thought of in terms of three pillars: economic, environmental and social [16].

In the race to meet the Intergovernmental Panel on Climate Change (IPCC) $1.5^{\circ} \mathrm{C}$ objective [14] we must cut emissions to net-zero by 2050. According to ITU-T [11] meeting targets requires a drastic reduction of the environmental footprint of the ICT industry by 2030 to half from 2015. Digital technologies are both part of the problem and part of the solution. Circularity, "designing out waste and pollution, keeping products and materials in use, and regenerating natural systems" [3], is a key way to implement sustainable development. Regarding digital devices, circularity aims at achieving the best use of these devices by extending their lifespan, that helps in decarbonising the environment. Moreover, circularity also can help reduce social inequality by delivering computing devices and creating jobs to a larger portion of the population. Therefore circularity contributes to sustainable development. Our research, leading the eReuse initiative in partnership with public and private organisations, has brought advances towards a circular economy of digital devices along the three pillars of sustainability.

Permission to make digital or hard copies of all or part of this work for personal or classroom use is granted without fee provided that copies are not made or distributed for profit or commercial advantage and that copies bear this notice and the full citation on the first page. Copyrights for components of this work owned by others than the author(s) must be honored. Abstracting with credit is permitted. To copy otherwise, or republish, to post on servers or to redistribute to lists, requires prior specific permission and/or a fee. Request permissions from permissions@acm.org.

(C) 2021 Copyright held by the owner/author(s). Publication rights licensed to ACM.

Manuscript submitted to ACM

The final publication is available at ACM via http://dx.doi.org/10.1145/3460112.3471973 


\section{THE eREUSE MODEL}

No longer used digital devices (computers, tablets, mobiles) are a resource for local social inclusion and participation. The eReuse initiative, outlined in [7] started in 2013, with an important milestone in 2015 with the launch of a computer donation campaign. By mid 2021 more than 10,000 computers have been processed with the eReuse software tools our team develops. Our vision is that public and private organisations act for the common good for a better, more inclusive and environmentally friendly internet, by donating their disposed devices to social enterprises as reuse centres that repair, refurbish and trace them to assess impact accountability. These devices are distributed to citizens that need these devices to participate over the Internet in education and socio-economic inclusion activities in their communities. This second-hand market creates social inclusion jobs and plenty of devices at the fair cost of refurbishment, as well as contribute to reduce our environmental footprint.

The eReuse model and software tools were outlined in [7], managed as a digital commons [4] and [5], measuring circularity metrics in [6], with [19] that provides an extensive analysis of our recent experience. This recent analysis shows more than 1,000 computers ${ }^{1}$ successfully refurbished in Barcelona by social inclusion workers in local social enterprises, according to our model and tools. These devices are used by vulnerable citizens in Barcelona, with an expected extended reuse lifespan of 2-3 years, and a significant reduction of environmental impact from the substitution of purchase of new devices.

Not only our research but also the value of eReuse for all participants is the ability to certify sustainability impacts as well as aggregate open data about circularity of devices, while preserving personal privacy and organisational confidentiality. Any sensitive data involving humans is removed by encryption, summary or aggregation. Human participants decide what device data they want to share with others and us, defined by the eReuse device data commons license [5]. Our research and practices are aligned with the European GDPR and complies with the ethical guidelines of our university.

\section{Activism}

To implement that aim, we have worked to bootstrap collaborative local circular economy ecosystems across stakeholders in the ICT circular supply chain of device reuse and recycling. eReuse has coordinated forums with different stakeholders that exchange complementary resources, skills, to balance supply and demand, share costs and help each other: device donors, refurbishers, citizen support organisations, recyclers that are part of a common-pool resource system of second-hand digital devices for an extended lifespan in use [4]. We call them "local circuits".

In Barcelona, we have 1,079 devices in common property, with more under individual property. The devices came from 45 different donor organisations and, after testing and refurbishment by 15 active social enterprises, were received by about 84 entities such as schools, public facilities, NGO, and final beneficiaries. Refurbished devices are prepared by workers of six social enterprises or reuse centres, associated to Barcelona's circuit. Devices have a (refurbishment) cost that is paid by either sponsors or receivers to refurbishers (as processing cost, since devices come from donation), in the range of 40-140€ each. During the COVID crisis $^{2}$ supported a service learning project to involve volunteers and social enterprises in the preparation of more devices for school students in need of computers to participate in distance learning during the confinement.

In 2018, the eReuse circuit model, as well as its software tools and data services, was replicated in Madrid by Asociación cultural La Kalle-ReutilizaK, a historical entity in the neighbourhood of Vallecas that, among others, seeks the social and labour inclusion of vulnerable young people through the preparation and reuse of electronic devices. It promoted an ecosystem together with two more entities (Vortex and RecuMadrid) so called the Sempiterna circuit. Since they started, they have reused and traced a total of 950 devices donated by 14 companies and given to 23 intermediary entities (NGO and schools).

${ }^{1}$ The eReuse open dataset 2019: https://dsg.ac.upc.edu/ereuse-dataset

${ }^{2}$ The Centre of Cooperation for Development at UPC.EDU: https://www.upc.edu/ccd/en 


\section{Circular business models}

We have developed a servitised business model where users pay for computing as a service, for instance according to the number of operational computers in a school classroom. Actors of the circuit ensure computer maintenance, upgrades, spare devices and replacement to comply with the service level agreement of a service contract for a monthly or yearly fee. This in turn ensures users have the computing service they need but device ownership remains in the circuit, so that devices perform well until they cannot satisfy anyone, when they are finally recycled and some parts reused. These recyclers are specialised in e-waste, and can be either public, commercial or social enterprises. They participate in the eReuse data by accepting the data commons license, registering the devices they receive and sharing data about them for circular traceability. Overall that allows to generate public datasets about impacts and the durability of devices we share and process [8]. All these activities become incentives to improve the longevity of devices for new reuse cycles that can benefit more people while mitigating the impact of digital technologies to the planet. The experience has allowed us to contribute to the ITU-T L.1024 [12] recommendation. The model has been further developed in the DLT4EU [10] challenge of the Sant Boi city in Catalonia.

\section{Policy}

We have developed a participation and data sharing license[4] and agreements with public and private device donors, maintainers, social organisations (NGO) working with end-users, social enterprises in social inclusion programs focused on refurbishment and recycling of digital devices. These agreements allow us collecting data about devices (the circular chain of custody), data aggregation and analysis of social impact (usefulness of additional computing hours enabled) and environmental impact $\left(\mathrm{CO}_{2} \mathrm{e}\right.$ savings). The donation of decommissioned devices from the Barcelona City Council, via an agreement with an ecosystem management entity that represents eReuse, has inspired and facilitated a set of public and private sector donations. This policy learning good practice has been published in the Interreg Europe Policy Learning Platform [2].

Building on existing experiences, we are consolidating [17] this knowledge into policy templates and help other policymakers to maximise the lifespan of the devices they procure, share and aggregate anonymised data for social and environmental accountability, while supporting local reuse centers and second hand markets, with special attention in supplying devices to otherwise disconnected citizens.

We have been able to identify administrative barriers that slow down or block policy change. For instance, we wanted to deploy secondhand devices in public schools, a target with high environmental, social and educational awareness potential. Although technically and economy feasible, huge administrative and bureaucratic hurdles caused that only five schools opted in for reuse to equip their computer classrooms over a two year period.

\section{Research and experimentation}

Beyond the software tools to capture data about computer devices, we have developed and adapted the eReuse device data capture software to mobile phones. In collaboration with two reuse centres we developed tools for inventory and traceability of mobile phones, defining protocols and documentation to control the quality of refurbishment. Beyond technology, an important aim of the project was the detection of barriers to mobile phone reuse, some placed by software developers when the firmware or operating system of a device is no longer maintained, by hardware manufacturers with lack spare parts or maintenance documentation, others placed by the last owner or operators, who didn't unlock terminals before discarding them.

We have explored how data about the circular lifespan of devices can be reported and verified to provide a "digital twin", the inventory information kept by a device owner. We also keep a digital ledger with annotations made by a trusted "digital notary" that allows ensure accountability and traceability of circular lifespan, and allows reporting in that ledger 
proofs of important actions like purchase, data wipe, transfer, repair and final recycling, conceptually equivalent to the digital tachographs for vehicles but stored externally. We implemented (EU Ledger[9] and Spanish SWEDGE projects) a permissioned ledger with an Ethereum PoA and smart contracts that implement conditional rewards that automatically return an economic deposit when a condition is met (e.g. return a device when no longer used or recycle when no longer usable). We implemented (EU DLT4EU[10] project) a set of proofs and an impact reporting mechanism linked to the ledger. We are currently offering an experimental API and ledger testbed (NGI Atlantic[18] project for EU-US collaboration) to support a pilot device accountability system developed in collaboration with the Obada Foundation. We have also explored (ChistERA LeadingEdge[1] project) the performance, scalability and decentralization of the required cloud services given the large volume of devices and events to manage.

All these experiences have contributed to propose and get approval from ITU-T of a new work item on the "Requirements for a global digital sustainable product passport to achieve a circular economy"[13].

\section{Useful resources}

To ensure efficiency, transparency and accountability in the reverse supply chain, we developed open software tools ${ }^{3}$ [7] to quickly and easily extract details, for the diagnostic and automation of inventory, for triage and preparation of second hand devices, for the generation of QR codes to stick on devices for traceability, as well as data formats and tools to collect and store data about the lifespan of each device, and finally for computing open data about impacts and reports.

\section{Overall impacts}

The main overall impact and outcomes confirm that we are in a good track to reduce the environmental impact of digital devices, with $\mathrm{CO}_{2}$ equivalent impact estimates that can be extracted from our ledger records. We have witnessed progress to the universalisation of access to computer devices, from the these low cost second-hand computers creating additional computing usage hours. The circular economy facilitates the creation of jobs in computer refurbishment, linked to device collection and refurbishment, as well as the reduction of ICT e-waste with longer usage lifespan through reuse. Software tools facilitate more efficient (time, quality) processing of digital devices, which implies less refurbishment time per device, that results in lower processing cost and higher efficiency and income for refurbishers. The collection and aggregation of privacy-preserving reliable open data allows to quantify and certify actual impacts promote circularity (chain of custody, responsibility) with the design of more durable products.

\section{ACKNOWLEDGMENTS}

This work was partially funded by the Spanish Government under contracts PID2019-106774RB-C21, and PCI2019111851-2 (LeadingEdge Chist-era), and the Generalitat de Catalunya as Consolidated Research Group 2017-SGR-990, the NGI DLT4EU, NGI Policy in Practice, NGI Atlantic projects, Subtract (Interreg Europe), the Association for Progressive Communications (APC), and the Waste Agency of the Catalan government.

Many organisations and people have participated in eReuse circuits and have contributed to improving the model: Pangea.org supporting the eReuse project since its initial idea, the Centre of Cooperation for Development at UPC, the city councils of Barcelona, Sant Boi and Getafe, and the entities part of eReuse: La Kalle-ReutilizaK, Solidança, Donalo.org, Andròmines-Alencop, Fundación Esplai, Trinijove, TXT-UPC, Banc dels Aliments, Abacus, Sant Joan de Déu-Terres de l'Ebre, Punt de referència, among others.

\footnotetext{
${ }^{3}$ Software repositories: https://www.eReuse.org/software/ and https://github.com/eReuse
} 


\section{REFERENCES}

[1] French National Research Agency. 2021. LeadingEdge - Holistic and foundational resource allocation framework for optimized and impactful edge computing services. Chist-era. Retrieved May 1, 2021 from https://www.chistera.eu/projects/leadingedge EU funded project.

[2] Interreg Europe. 2021. Socially minded platform for the reuse and recycling of Electrical and Electronic Equipment (EEE). Interreg Europe. Retrieved Abril 1, 2021 from https://www.interregeurope.eu/policylearning/news/11475/socially-minded-platform-for-the-reuse-and-recycling-of-electricaland-electronic-equipment-eee/ Policy Learning Platform.

[3] Ellen McArthur Foundation. 2017. What is the circular economy? Ellen McArthur Foundation. Retrieved Abril 1, 2021 from https://www.ellenmacarthurfoundation.org/circular-economy/what-is-the-circular-economy

[4] David Franquesa and Leandro Navarro. 2017. Sustainability and participation in the digital commons. ACM Interactions 24, 3 (2017), $66-69$. https://doi.org/10.1145/3058139

[5] David Franquesa and Leandro Navarro. 2018. Devices as a Commons: Limits to Premature Recycling. In Proceedings of the 2018 Workshop on Computing within Limits (Toronto, Ontario, Canada) (LIMITS '18). Association for Computing Machinery, New York, NY, USA, Article 8, 10 pages. https://doi.org/10.1145/3232617.3232624

[6] David Franquesa, Leandro Navarro, Stephan Fortelny, Mireia Roura, and Jordi Nadeu. 2019. Circular consumption and production of electronic devices: an approach to measuring durability, upgradeability, reusability, obsolescence and premature recycling. In The European Roundtable for Sustainable Consumption and Production - Circular Europe for Sustainability, Barcelona. UPC, Barcelona, Spain, 196-197.

[7] David Franquesa, Leandro Navarro, David López, Xavier Bustamante, and Santiago Lamora. 2015. Breaking Barriers on Reuse of Digital Devices Ensuring Final Recycling. In 29th International Conference on Environmental Informatics, EnviroInfo 2015 / 3rd International Conference on Information and Communication Technology for Sustainability, ICT4S 2015, Copenhagen, Denmark. Atlantis Press, Amsterdam, Netherlands, $281-288$.

[8] David Franquesa, Mireia Roura, and Leandro Navarro. 2020. eReuse datasets, 2013-10-08-2019-06-03. UPC. Retrieved May 1, 2021 from https://dsg.ac.upc.edu/ereuse-dataset

[9] BLUMORPHO FundingBox, Dyne. 2021. The Venture Builder for Human Centric Solutions. Next Generation Internet program. Retrieved May 1, 2021 from https://ledgerproject.eu EU funded project.

[10] Ideas4Change. 2021. Connecting Distributed Ledger Technology (DLT) to social and environmental challenges across the European Union. Ideas4Change. Retrieved May 1, 2021 from https://www.dlt4.eu EU funded project.

[11] ITU-T. 2020. NGHG emissions trajectories for the ICT sector compatible with the UNFCCC Paris Agreement,. ITU-T. Retrieved Abril 1, 2021 from https://www.itu.int/rec/T-REC-L.1470-202001-P Recommendation ITU-T L.1470.

[12] ITU-T. 2021. The potential impact of selling services instead of equipment on waste creation and the environment - Effects on global information and communication technology. ITU-T. Retrieved Abril 1, 2021 from https://www.itu.int/rec/T-REC-L.1024 Recommendation ITU-T L.1024.

[13] ITU-T. 2021. SG5: Environment, climate change and circular economy. ITU-T. Retrieved May 1, 2021 from https://www.itu.int/en/ITUT/studygroups/2017-2020/05/Pages/default.aspx Work item on draft Recommendation ITU-T L.GDSPP Requirements for a global digital sustainable product passport to achieve a circular economy.

[14] V. Masson-Delmotte et al. 2018. Special report Global warming of $1.5^{\circ} \mathrm{C}$. Technical Report. Intergovernmental Panel on Climate Change. https://www.ipcc.ch/sr15/

[15] United Nations. 1987. Our common future. United Nations. Retrieved May 1, 2021 from http://www.un-documents.net/our-common-future.pdf Also known as The Brundtland Report.

[16] United Nations. 2005. World Summit Outcome, Resolution A/60/1. United Nations. Retrieved May 1, 2021 from https://www.un.org/en/development/ desa/population/migration/generalassembly/docs/globalcompact/A_RES_60_1.pdf adopted by the General Assembly on 15 September 2005.

[17] Leandro Navarro. 2021. Policy in Practice Fund: Reducing the digital divide by improving the circular economy for devices. NGI PIP. Retrieved May 1, 2021 from https://research.ngi.eu/policy-in-practice-fund-reducing-the-digital-divide-by-improving-the-circular-economy-for-devices/ PiP.

[18] Waterford Institute of Technology. 2021. NGIatlantic.eu - A Collaborative platform for EU-US Next Generation Internet Experiments. Next Generation Internet program. Retrieved May 1, 2021 from https://ngiatlantic.eu EU funded project.

[19] Mireia Roura, David Franquesa, Leandro Navarro, and Roc Meseguer. 2021. Circular digital devices: lessons about the social and planetary boundaries. In Proceedings of the 2021 Workshop on Computing within Limits (virtual) (LIMITS '21). Association for Computing Machinery, New York, NY, USA, Article 21, 10 pages. https://computingwithinlimits.org/2021 